\title{
GREENWASHING: O FALSO MARKETING E A RESPONSABILIDADE CIVIL EM RELAÇÃO AO CONSUMIDOR
}

\author{
Gabriela Amorim Paviani ${ }^{1}$
}

Resumo: A tutela do meio ambiente ganha espaço nas políticas empresariais, especialmente, para conquistar credibilidade perante os consumidores. Entretanto, é oportuno questionar até que ponto o marketing verde condiz com as práticas efetivas das corporações? Neste sentido a pesquisa está voltada à análise do greenwashing, termo que remete às condutas empresariais de falso marketing e que induzem o consumidor a erro. Se tal prática for comprovada tem-se possibilidade de responsabilização civil à luz dos princípios da boa-fé, transparência e direito a informação verdadeira. Parta tanto, utilizar-se-á no método dedutivo, a partir de pesquisas bibliográficas.

Palavras-chave: Marketing verde; Greenwashing; Sustentabilidade; Responsabilidade civil; Consumidor.

\section{GREENWASHING: FALSE MARKETING AND CIVIL LIABILITY WITH RESPECT TO THE CONSUMER}

\begin{abstract}
The protection of the environment gains space in business policies, especially to gain credibility with consumers. However, it is timely to question the extent to which green marketing matches the effective practices of corporations? In this sense the research is focused on the analysis of greenwashing, a term that refers to misleading business conduct and that misleads the consumer. If such practice is proven, there is a possibility of civil accountability in the light of the principles of good faith, transparency and the right to truthful information. So far, it will be used in the deductive method.
\end{abstract}

Keywords: Green marketing; Greenwashing; Sustainability; Civil Responsibility Consumer

\footnotetext{
${ }^{1}$ Mestranda em Direito Negocial e Especialista em Direito Empresarial pela Universidade Estadual de Londrina. Bolsista CAPES. Especialista em Direito e Processo do Trabalho pela Universidade Estácio de Sá. Bacharel em Direito pela Pontifícia Universidade Católica do Paraná Advogada.

E-mail: gabrielapaviani@gmail.com
} 


\section{INTRODUÇÃOO}

Em decorrência da globalização, e, por conseguinte, de uma nação cosmopolita, iniciase a discussão quanto a proteção do meio ambiente, a partir da conceituação de desenvolvimento sustentável e economia ecológica.

Deste modo, quando os homens passaram a ter a noção quanto a finitude e limitação do meio ambiente, considerando os riscos e danos transnacionais, cresce a preocupação quanto ao seu resguardo, seja pelo Estado, Empresa e Sociedade como um todo.

Nessa sequência, tem se tornado um tema de suma importância e de grandes discussões, a responsabilidade social empresarial, principalmente ao que tange a proteção ambiental e sustentabilidade.

Com o decorrer do tempo, devido a essa mudança de paradigma em todo o globo, produtos e serviços que fazem uso de sistemas de produção ecologicamente corretos, seja por meio da utilização de matérias primas menos danosas, alterações do modo de extração e práticas pouco nocivas que causam menos impactos ambientais, passaram a ganhar valor de mercado, sendo um destaque positivo, tanto para fidelização de clientes, como o de investidores.

Diante dessa realidade, a ciência do marketing passou a fazer uso desse novo ideal, enfatizando as práticas ecológicas das organizações, empresas e até mesmo entes estatais na busca da captação do mercado consumidor e investidor, tal atuação é comumente distinguida como marketing verde, aqui encarado como espécie do gênero marketing social.

A problemática ocorre quando as eco propagandas não passam de divulgações falsas, ao que tange efetiva ação de proteção ambiental pelas organizações, de modo a traduzir-se em um verdadeiro abuso de confiança do consumidor, além de uma prática antiética no mercado.

Para tanto, o presente estudo possui como foco a análise do termo greenwashing, também compreendido como maquiagem verde, qual seja o falso marketing sustentável, o que pode resultar em uma depreciação da luta por um desenvolvimento sustentável.

Por fim, como um meio de coibição, pugna-se pela responsabilidade objetiva do fornecedor do produto ou serviço quando diante da constatação de práticas antiéticas, anticoncorrenciais e de abuso de confiança, como é o caso do greenwashing, fazendo-se valer dos princípios elencados no Código Civil, bem como aqueles positivados no Código de Defesa do consumidor. 


\section{MARKETING VERDE E ECO PROPAGANDAS}

O meio ambiente possui uma vocação espacialmente transnacional, isso ocorre até de forma mais acentuada do que muitos outros direitos, uma vez que os interesses ambientais também gravitam em uma perspectiva ampliada no que diz respeito aos sujeitos, na medida em que envolve direitos das presentes e futuras gerações, bem como de toda a comunidade de vida.

É nesse cenário que surge a chamada economia ecológica, a qual alerta para o fato de que se a população continuar a duplicar a cada cinquenta anos, como se tem ocorrido nesses últimos anos, ou se o nível do consumo energético dos países desenvolvidos se estender ao resto do mundo, em poucas décadas se acabarão as reservas energéticas, chagando-se ao topo de uso de produtos da fotossíntese mundial (FOLADORI, 2001, p.143).

Os riscos globais, potencializados por eventos naturais extremos das últimas décadas e pela revolução tecnológica, incentivam novos pactos e estratégias de governança para a construção de uma nova civilidade global baseada eticamente na cooperação. É diante dessa realidade que a concepção de preservação ambiental e desenvolvimento sustentável passou a fazer parte integradora do valor que se é dado a um determinado produto, fazendo-se crescer o chamado marketing verde.

Quanto ao impacto da convicção sustentável no mercado, conforme os relatórios de pesquisa da Michael Peters Group, empresa se consultoria americana, foi constatado que no ano de 1989, 89\% dos consumidores dos Estados Unidos passaram a adquirir produtos e serviços que gerassem uma menor degradação ambiental, sendo que desses, 78\% estariam dispostos a pagar um valor maior por um produto "ecologicamente correto" (MAKOWER, 2009, p.10).

Nesse aspecto, diante das alterações relatadas, há o surgimento do chamado marketing social, que engloba o marketing verde, sendo que aquele não deve ser encarado apenas como uma tática de vendas passageira, visto que reflete exatamente a personalidade do corpo social.

Todavia, preliminarmente, antes de compreender o que seria o marketing social se faz fundamental responder o que se entende por marketing, de modo que "podemos definir o marketing como o processo social gerencial através do qual indivíduos e grupos obtém aquilo que desejam e de que necessitam, criando e trocando produtos e valores uns com os outros" (KOTLER e ARMSTRONG, 1998, p. 3). 
Portanto, tal ramo cientifico trabalha com determinados elementos, quais sejam: necessidades e demandas, desejos e satisfações, mercados, trocas e qualidades, posto que o "marketing é o processo de planejar e de executar a concepção, estabelecimento de preços, promoção e distribuição de ideais, produtos e serviços para criar trocas que satisfaçam metas individuais e organizacionais" (CHURCHILL e PETER, 2000, p. 4).

Diante dessas definições, é passível a compreensão de que o marketing possui duas funções: vender produtos, pelo seu viés gerencial, mas também, sob a ótica social, propagar ideias de desenvolvimento solidário, humano e sustentável. Por conseguinte, o marketing pode ser encarando por perspectivas diversas, conforme aduzem Lewis e Llttler, ao analisarem as pesquisas de Crosier:

Crosier (1988) analisou cerca de 50 definições e classificou-as em três amplos grupos. O primeiro consistiu nas definições que concebiam marketing como um processo que conecta o produtor a seu mercado (...) O segundo grupo consistiu nas definições que viam marketing como um conceito ou filosofia de negócio. (...) A terceira categoria de definições de Crosier enfatizava marketing como uma orientação presente em algum grau no consumidor e no produtor: o fenômeno que torna o processo e o conceito possíveis (LEWIS e LITTLER, 2001, p. 166).

É precisamente por compreender o papel de suma importância que o marketing exerce, mas também principalmente pelo fato das empresas começarem a se atentar quanto a importância, mesmo que a longo prazo, de satisfazerem os anseios dos consumidores, tanto pela qualidade dos produtos, quanto pela suas expectativas em relação política empresarial, bem como os interesses da própria sociedade, que surge o marketing social.

Ressalta-se que o termo marketing social é empregado pela primeira vez nos Estados Unidos, na década de 70, quanto estudiosos sobre o tema discutiam a capacidade de aplicação do marketing em problemáticas sociais, de modo que Kotler e Roberto explicam que:

o termo "marketing social" apareceu pela primeira vez em 1971, para descrever o uso de princípios e técnicas de marketing para a promoção de uma causa, idéia ou comportamento social. Desde então, o termo passou a significar uma tecnologia de administração da mudança social, associada ao projeto, à implantação e ao controle de programas voltados para o aumento da disposição de aceitação de uma idéia ou prática social em um ou mais grupos de adotantes escolhidos como alvo. (...) A instituição patrocinadora persegue os objetivos de mudança na crença de que eles contribuirão para o interesse dos indivíduos ou da sociedade (KOTLER e ROBERTO, 1992, p. 25). 
Impossível a desconexão do marketing social com as características próprias, intrínsecas, ao próprio marketing, principalmente ao que tange ao cumprimento de metas que não seja somente o lucro, mas a propagação de ideias de um desenvolvimento em sentido amplo. Sob essa perspectiva Lewis e Llttler ponderam que o:

marketing social trata do desenvolvimento de programas destinados a influenciar a aceitação de idéia sociais, e pode ser definido como um conjunto de atividades para criar, manter e/ou alterar atitudes e/ou comportamentos em relação à idéia ou causa social, independentemente de uma organização ou pessoa patrocinadora" (LEWIS e LITTLER, 2001, p. 183).

As organizações, após perceberem que a adoção de políticas sociais, sejam ambientais, de gênero, raça, entre outras, acarretam em valorização de seus produtos no mercado, passaram a adotar as técnicas do marketing social, entretanto, cabe esclarecer que a utilização desse recurso não é considerado inovador, tendo início no século XX.

Desta maneira, Melo Neto e Froes, quanto a utilização do marketing como meio de gerar lucro nos investimentos empresariais, afirmam quem:

Mais uma vez a 'inteligência empresarial' funcionou, e muito bem. Surgiu a necessidade de comunicação dessas ações sociais para o mercado, o que culminou com a emergência do marketing social. As empresas aprenderam a obter retorno de seus investimentos na comunidade. Assim, de objeto de ações filantrópicas, a participação no sentido de prover condições para o melhor desenvolvimento social, tornou-se alvo de ações de comunicação e marketing social (MELO NETO e FROES, 2001, p. 10).

Corroborando com tal perspectiva, o Marketing para Causas Sociais como estratégia, segundo Pringle e Thompson, é assim definido:

O Marketing Social para Causas Sociais (MCS) pode ser definido como uma ferramenta estratégica de marketing e de posicionamento que associa uma empresa ou marca a uma questão ou causa social relevante, em benefício mútuo (PRINGLE e THOMPSON, 2000, p.3).

Além da valoração de uma empresa, serviço ou produto, o marketing social também pode ser empregado como um difusor de certos comportamentos, podendo contribuir e promover determinadas atitudes e procedimentos, fazendo uso de suas capacidades como ciência e avanços tecnológicos para um bem maior, de modo que Kotler e Roberto enfatizam: 
A possibilidade de uma vida melhor através de mudanças em idéias e processos sociais não é amplamente percebida em muitas partes do mundo; pelo contrário, a resignação com a ordem vigente - uma atitude fatalista - é o que predomina. Por essa razão, as campanhas de mudança social e o marketing social não são simplesmente um conjunto de instrumentos para a consecução de mudança social. Representam uma nova ideologia, ou estado de espírito, cuja assimilação pode preparar o terreno para a mudança social generalizada e mais eficaz (KOTLER e ROBERTO, 1992, p. 31).

Quanto ao marketing verde, aqui entendido como espécie de marketing social, esse diz respeito aos incentivos, por meio de técnicas de publicidade, à comercialização de produtos e serviços os quais denigram em menor grau o meio ambiente, seja através de modificações na extração de matéria prima, alterações na embalagens, ou até mesmo a transfiguração do próprio produto (POLONSKY, 1994).

A criação de produtos sustentáveis, orientados por um viés ecológico, seja por consumir menos matéria prima, ou por gastar menos energia em sua produção, são o objeto do marketing verde, marketing defino por Jöhr como “(...) colocar os objetivos de marketing em termos ecológicos" (JÖHR ,1994, p. 86).

Esclarece-se que um produto que segue os liames ambientais, o qual se pauta por um desenvolvimento ecologicamente sustentável, possui algumas características determinadas, o que Ottman aponta classifica:

Fabricado com a quantidade mínima de matérias primas e com matérias primas renováveis, recicláveis e que conservem recursos naturais no processo de extração; fabricado com a máxima eficiência energética de utilização de água e com o mínimo despejo de afluentes e resíduos; envasado em embalagens mais leves e mais volumosas; Ser concentrado, mais durável, ser utilidade para múltiplos propósitos, ser mais facilmente consertado, ter maios eficiência e Energética quanto utilizado, ser reciclável, ser reutilizável, ser biodegradável, pode ser refabricado e poder ser substituído por refil (OTTMAN, 1994, p.57).

Além de divulgar os atributos sustentáveis do produto ou serviço do produto, o marketing verde também se faz responsável por enaltecer e divulgar práticas associadas a sustentabilidade, praticadas pelo corpo empresarial, ao passo que Cortez afirma que:

(...) o marketing ambiental tem como objetivos-chave: desenvolver produtos que equilibrem necessidade dos consumidores e preço viável, além de exercerem um impacto mínimo sobre o ambiente; projetam uma imagem de alta qualidade, incluindo a preocupação ambiental, quanto aos atributos do 
produto e quanto à trajetória do seu fabricante no que diz respeito ao meio ambiente (CORTEZ , 2007, p.31).

Sabe-se que o objetivo central do marketing é a diferenciação de produto e serviços no extenso e concorrido mercado consumidor, de modo que cabe as propagandas publicitárias enfatizarem as qualidades de seus produtos, a fim de convencerem os consumidores a escolherem os seus produtos em detrimento de outros.

Por sua vez, as eco propagandas possuem a mesma finalidade, conquanto que a diferenciação dos seus produtos ou serviços residem na questão ambiental, enfatizando-se o meio de produção e opção de matérias primas que denigram em menor patamar o meio ambiente.

\section{SINGNIFICADO E CONSEQUÊNCIA DO GREENWASHING}

Aglutinação do inglês green, que significa verde, e washing, lavando, o termo greenwashing, corresponde, em tradução livre, lavagem verde, mas também pode ser compreendido como "maquiagem verde", ocorrendo quando as organizações se valem da política ambiental para promoverem um produto ou serviço, sendo que na realidade, busca-se apenas o lucro.

O termo, por vezes também faz referência à whitewashing, nomeação muito empregada no mercado de capitais, traduzindo-se por: branqueamento de capitais ou lavagem de dinheiro. De qualquer modo, o substantivo no português pode aparecer como: lavagem verde, lavagem ecológica, maquiagem verde, pintando de verde.

Cabe ressaltar que o greenwashing não necessariamente pode ser praticado apenas por empresas privadas, como se faz denotar em um primeiro momento, mas por todas as instituições que objetivam obter vantagens utilizando-se de técnicas de proteção ambiental que não correspondem com a realidade.

Desta maneira, as instituições que não alteram seu modo de produção ou matéria-prima em prol do meio ambiente, mas se valem da divulgação de "suas práticas ecológicas", a fim de aproveitar-se da tendência social mercadológica, se tem o chamado greenwashing, o que Café aponta:

As empresas descobriram que o consumidor passou a valorizar quem investe em sustentabilidade. Mas sempre há aqueles que se aproveitam para dizer o 
que não fazem ou até mesmo mudam a cor de suas embalagens ou de seus anúncios para o verde, como se isso fosse sinal de compromisso com o meio ambiente (CAFÉ, 2010, p.45).

Entretanto, o greenwashing não se trata apenas de informações enganosas em desfavor da população, eco propagandas falsas, promessas publicitárias de ecoeficiência, estratégias de marketing verde, que visam disseminar desinformação ou manipulação de alguma informação para favorecer a empresa, é muito maior do que isso, trata-se de por em cheque os compromissos assumidos por essas empresas e organizações em ações direcionadas a proteção do meio ambiente.

As eco propagandas, como o já demonstrado, possuem um papel de extrema relevância no que diz respeito ao compromisso com questões ambientais, posto ser o meio direto de contato com o consumidor, o induzindo não raras vezes ao erro. É nesse diapasão que a Associação Brasileira de normas técnicas, consoante aos pensamentos de Terra Choice, classificam em os sete pecados da rotulagem ambiental, quais sejam:

Pecado do Custo Ambiental Camuflado: É uma declaração de que um Produto é "verde" baseado apenas em um conjunto restrito de atributos sem atenção a outras importantes questões ambientais. Papel, por exemplo, não é necessariamente ambientalmente preferível apenas pelo fato de vir de uma floresta plantada sustentavelmente. Outras importantes questões no processo de produção do papel, tais como a emissão de gases de efeito estufa ou a utilização de cloro no branqueamento do papel podem ser igualmente importantes.

Pecado da Falta de Prova: Uma declaração ambiental que não pode respaldada informação de suporte facilmente acessível ou por uma certificação de terceira parte confiável. Exemplos comuns são produtos como lenços de papel ou papel toalha, que declaram várias porcentagens de conteúdo reciclável pós-consumo, sem fornecer evidência.

Pecado da Incerteza: Uma declaração que é tão pobre ou abrangente que seu real significado provavelmente não será compreendido pelo consumidor. "Totalmente natural" é um exemplo. Arsênico, urânio, mercúrio e formaldeídos são de ocorrência totalmente natural, e venenosos. "Totalmente natural" não é necessariamente "verde".

Pecado da Irrelevância: Uma declaração ambiental que pode ser verdadeira, mas não é importante ou é inútil para os consumidores que buscam produtos ambientalmente preferíveis. "Livre de CFC" é um exemplo comum, já que é um apelo freqüente apesar do fato de que os CFCs estão banidos por lei.

Pecado do "Menos Pior": Uma declaração pode ser verdadeira na categoria do Produto, mas que arrisca distrair o consumidor do maior impacto ambiental da categoria como um todo. Cigarros orgânicos podem ser um exemplo deste Pecado, tanto quanto veículos utilitários eficientes no consumo de combustível. 
Pecado da Mentira: Declarações ambientais que são simplesmente falsas. Os exemplos mais comuns eram produtos falsamente declarados como sendo certificados ou registrados pela eficiência energética ("Energy Star").

Pecado do Culto aos falsos rótulos: surge quando um produto, através de palavras ou imagem, tenta apresentar certificação emitida terceira parte, com o objetivo de desviar a atenção dos consumidores, por meio de falsos rótulos. Ex.: algumas marcas de desodorantes e outros produtos spray/aerossol que dão a impressão de uma certificação (ASSOCIAÇÃO BRASILEIRA DE NORMAS TÉCNICAS - ABNT).

Sem embargo, como meio de proteção do consumidor e verificação de propagandas, surge no Brasil, no ano de 1978, o Conselho de Auto-regulamentação Publicitária (CONAR), organização da sociedade civil fundada por entidades do mercado publicitário brasileiro para regular a publicidade no país. Diante disto, em 1980, O CONAR estipula a criação de um Código Brasileiro de Auto-Regulamentação Publicitária (CBARP), datado de 08 de maio de 1980.

Defronte as propagandas enganosas no que se refere a questão ambiental, em junho de 2011, foi criado o anexo U do CBARP, destacando a responsabilidade do anunciante para com o meio ambiente e sustentabilidade, segundo os princípios aqui apontados:

1. Concretude - Qualquer alegação de benefícios socioambientais deverá corresponder a práticas concretas adotadas, evitando-se conceitos vagos, com acepções equivocadas ou mais abrangentes do que as condutas apregoadas. Antes da publicidade a empresa deve demonstrar as posturas e condutas sustentáveis e ambientais que alega. 2.Veracidade - As informações e alegações veiculadas devem ser verdadeiras, passíveis de verificação e de comprovação

3. Exatidão e Clareza - As informações veiculadas deverão ser exatas e precisas, expressas de forma clara e em linguagem compreensível, não ensejando interpretações equivocadas ou falsas conclusões.

4. Comprovação e Fontes - Os responsáveis pelo anúncio devem dispor de dados comprobatórios e de fontes externas que endossem, senão mesmo se responsabilizem pelas informações socioambientais comunicadas.

5. Pertinência - As informações socioambientais devem ter relação lógica com a área de atuação das empresas, e/ou com suas marcas, produtos e serviços, em seu setor de negócios e mercado. 6. Relevância - Os benefícios socioambientais comunicados deverão ser significativos em termos do impacto global que as empresas, suas marcas, produtos e serviços exercem sobre a sociedade e o meio ambiente - em todo seu processo e ciclo, desde a produção e comercialização, até o uso e descarte.

7. Absoluto - Em razão dos possíveis impactos socioambientais produzidos pelas empresas, a publicidade não comunicará promessas ou vantagens absolutas ou de superioridade imbatível. As ações de responsabilidade socioambiental não serão comunicadas como evidência suficiente da sustentabilidade geral da empresa, suas marcas, produtos e serviços. 
8. Marketing relacionado a causas - A publicidade explicitará claramente $\mathrm{a}(\mathrm{s})$ causa(s) e entidade(s) oficial(is) ou do terceiro setor envolvido(s) na parceria com as empresas, suas marcas, produtos e serviços. O anúncio não poderá aludir a causas, movimentos, indicadores de desempenho nem se apropriar do prestígio e credibilidade de instituição a menos que o faça de maneira autorizada. As ações socioambientais e de sustentabilidade objeto da publicidade não eximem anunciante, agência e veículo do cumprimento das demais normas éticas dispostas neste Código. (CBARP, 2011).

Entretanto, o CONAR por não ser um órgão estatal, esse não possui o direito de exercer poder de polícia, portanto, suas normas não são vinculativas e inexistente a possibilidade de aplicação de multas, sendo que as organizações que o apoiam, o fazem de maneira voluntária. Entretanto, apesar de não possuir força judicial, os pareceres emitidos pelo CONAR influenciam nas decisões, bem como nas escolhas dos consumidores e de investidores externos.

Por conseguinte, a prática do greenwashing gera um enfraquecimento da luta ambiental, o qual busca a real e efetiva mudança dos modos de produção, voltando-se a uma promoção sustentável e defesa da natureza,

\section{GREENWASHING: UMA AFRONTA AO DESENVOLVIMENTO SUSTENTÁVEL}

Quanto ao dano ecológico, e sua consequência transnacional, capaz de ultrapassar barreiras geográfica, Zenildo Bodnar e Paulo Márcio Cruz esclarecem que:

A crise ecológica, além de ser espacialmente global, não significa apenas o descompasso entre a geração de bens e serviços ambientais e a sua utilização antrópica. É, na verdade, a crise da própria civilização contemporânea. O modo de organização política não é mais adequado às novas demandas transnacionais (BODNAR, CRUZ, 2016, p. 236)

Assim, diante do risco iminente de destruição ambiental é que a proteção e desenvolvimento sustentável passou a ser defendido em escala mundial pelos Direitos Humanos, exatamente por este refletir um conteúdo axiologicamente construído a partir de lutas sociais.

A expansão da industrialização e da exploração de áreas agrícolas e mineral gerou efeitos deletérios sobre o meio ambiente de muitas regiões, o que provocou o surgimento de diversas iniciativas, com o objetivo de criar áreas protegidas das ações humanas e onde a vida selvagem pudesse ser preservada. 
Ressalta-se que um ambiente ecologicamente equilibrado é um elemento imprescindível no que diz respeito a uma saudável qualidade de vida, sendo também por essa razão o relacionamento direto dos Direitos Humanos e do Direito Ambiental, posto que possuem como objetivo central em comum a preservação da digna qualidade de vida dos indivíduos.

Foi no ano de 1972, em Estocolmo, com a Conferência das Nações Unidas sobre o Meio Ambiente Humano, em Estocolmo, que foi discutido pela primeira vez no âmbito internacional a preservação do meio ambiente e o desenvolvimento, entretanto, foi somente em 1987, a partir da publicação do relatório Nosso Futuro Comum, mais famoso como Relatório de Brundland é que o conceito de desenvolvimento sustentável foi divulgado. Portanto, o desenvolvimento sustentável, a luz de tal relatório ficou conceituado como "aquele que atende as necessidades do presente sem comprometer as possibilidades de as gerações futuras atenderem suas próprias necessidades".

Por sua vez, em 1992, no Rio de Janeiro, com a Conferência das Nações Unidas para o Meio Ambiente e o Desenvolvimento é que tal conceituação fora dissipada mundialmente, passando ser o meio ambiente encarado como um bem limitado, que se danificado, difícil e por vezes inexistentes a sua recuperação.

Quando há uma degradação ambiental, indubitavelmente estar-se diante de consequências catastróficas que atingem toda a sociedade, por exemplo cita-se os desastres, entretanto, essa mesma sociedade que sofre em decorrência da depredação ambiental, é a mesma que prima pelo consumo desmedido, em detrimento dos bens naturais, ao passo que Bobbio enfatiza que:

(...) o problema grave do nosso tempo, com relação aos direitos do homem, não era mais o de fundamentá-los, e sim o de protegê-los. (...) Não se trata de saber quais e quantos são esses direitos, (...) mas sim qual é o modo mais seguro de garanti-los para impedir que, apesar de solenes declarações, eles sejam continuamente violados. (...) (BOBBIO, 1992, p. 25)

É a partir desse cenário de um mundo globalizado, considerando o meio ambiente salutar como um Direito Humano e Fundamental, haja a vista a proteção do meio ambiente 
primordialmente a luz do artigo 225 da Constituição Federal ${ }^{2}$, é que as empresas começaram a exercer um papel de grande importância nas questões em envolvem as problemáticas sociais e ambientais, muitas vezes substituindo as atribuições que antigamente eram somente do ente Estatal.

Neste ínterim, as empresas também devem se adequar, e adotar um agir maior do que a função social que lhes são atribuídas legalmente pelo Código Civil e pela Constituição Federal Brasileira, cabendo as mesmas possuir pautar-se seu agir na responsabilidade social.

Ressalta-se que a responsabilidade social, ambiental vem a ser a "decisão de participar mais diretamente das ações comunitárias na região em que está presente e minorar possíveis danos ambientais decorrente do tipo de atividade que exerce" (1998 apud MELO NETO e FROES, 2002, p. 78).

A empresa sustentável é aquela que procura incorporar os conceitos e objetivos relacionados com o desenvolvimento sustentável em suas políticas e práticas de modo consistente, adotando como diretrizes pactos internacionais, por exemplo: Declaração universal dos direitos humanos; Agenda 21; Carta da Terra; Metas do Milênio.

Desta maneira, as instituições que fazem uso do marketing verde para a promoção de seus produtos, quando sua publicidade se dá de maneira enganosa, no que diz respeito a defesa do meio ambiente equilibrado, além de ser uma afronta direta aos consumidores, trata-se de uma verdadeira ofensa à busca de um desenvolvimento sustentável, acarretando em um dano coletivo e porque não infra geracional.

\section{A RESPONSABILIZAÇÃO OBJETIVA QUANTO AO CONSUMIDOR}

Devido a Revolução Industrial ocorrida no Sec. XIX, o padrão de consumo dos seres humanos mudou drasticamente, como também os níveis de produção, passando a população a arcar com as problemáticas decorrentes da escassez da matéria base.

Atualmente, a conscientização cosmopolita de que os recursos naturais devam estar pautados pelo uso eficiente dos mesmos, a partir de uma utilização equilibrada dos meios naturais para a produção e consequente utilização dos produtos e serviços no mais diversos

\footnotetext{
2 Art. 225. Todos têm direito ao meio ambiente ecologicamente equilibrado, bem de uso comum do povo e essencial à sadia qualidade de vida, impondo-se ao Poder Público e à coletividade o dever de defendê-lo e preserválo para as presentes e futuras gerações.
} 
meios, é que o ideal de sustentabilidade passou a agregar valor de venda nesses mesmos produtos e serviços.

Por conseguinte, diante da valorização de um consumo sustentável, os meios de comunicação de publicidade das instituições passaram a fazer uso dessa concepção para a divulgação de seus produtos e serviço, nesse sentido, Érico Luciano Pagotto expõe:

Por meio dos casos apresentados até aqui, é fácil observar fácil que a publicidade vem se utilizando cada vez mais de apelos ambientais e ecológicos para a promoção de empresas, seus produtos e serviços. Isso inclui não apenas os segmentos industriais, mas praticamente todos os setores econômicos, como por exemplo, concessionárias de serviços públicos, como energia, saneamento, transportes, entre outros, estabelecimentos varejistas, prestadores de serviços, e até mesmo empresas e órgãos públicos nas três esferas de governo (PAGOTTO, 2013, p.140).

A convicção da necessidade de um consumo, bem como de um desenvolvimento sustentável, vem ganhando notoriedade e espaços cada vez maiores no cenário global, tanto que o Programa das Nações Unidades para o Meio Ambiente, a luz de Santos e Silva, defende que:

O fornecimento de serviços e de produtos correlatos que preencham as necessidades básicas e deem uma melhor qualidade de vida, ao mesmo tempo em que diminui o uso de recursos naturais e substancias tóxicas, assim como as emissões de resíduos e de poluentes durante o ciclo de vida do serviço ou do produto, de forma a não ameaçar as necessidades das gerações futuras (PNUD, 1998, p.65 apud SANTOS e SILVA, 2011).

Consequentemente, é essencial o envolvimento de toda a sociedade civil e empresária, bem como o Estado para a promoção de um bem maior, qual seja a não degradação ambiental, de modo que Leite afirma:

Não se pode adotar uma visão individualista sobre a proteção ambiental, sem solidariedade e desprovida de responsabilidades difusas globais. Trata-se de um pensamento equivocado dizer que os custos da degradação ambiental devem ser repartidos por todos, em uma escala global que ninguém sabe calcular. Esta visão é distorcida e leva ao esgotamento total dos recursos ambientais e a previsões catastróficas. Portanto, somente com a mudança para a responsabilização solidária e participativa dos estados e dos cidadãos com os ideais de preservação ecológica é que será possível encontrar solução para a crise ambiental (LEITE, 2007, p.160).

É nesse sentido que as boas práticas de sustentabilidade ganham relevância na decisão dos consumidores, passando a publicidade extrapolar as ideias básicos quanto a utilização de 
cores e outros artifícios comuns do marketing, englobando palavras e expressões que convergem na sustentabilidade, sendo as mesmas empregadas para induzir o consumidor. Quanto a tal fato preponderante, Makower expõe:

Pesquisadores descobriram que algumas afirmações de rótulos eram imprecisas, inverificáveis ou simplesmente sem significado. Muitas das expressões utilizadas - seguro, amigo do planeta, não tóxico, orgânico e natural, entre outras - não tinham uma definição legal ou geralmente aceita. Ainda outras eram tecnicamente verdadeiras, mas funcionalmente falsa (MAKOWER, 2009, p.13).

A problemática se dá quando os publicitários passam a se utilizar, de má fé, a defesa da sustentabilidade para promoverem seus produtos e serviços, quando que na realidade a instituição não se faz adepta dos meios ecologicamente corretos, enganando os consumidores para fins de venda.

Tal ato é uma verdadeira afronta ao consumidor, sendo considerado um abuso de confiança por parte da organização, gerando um descrédito desse produto ou serviço, bem como da marca, de modo que Lavorato aduz:

Na visão do consumidor, muito se fala, pouco se prova, e talvez por isto haja descrédito e falta de motivação para um consumo norteado pelos critérios da sustentabilidade. Fica claro que os consumidores esperam das organizações mais consistência e evidências da sustentabilidade informada (LAVORATO, 2010, p.38).

Além disso, verifica-se que o greenwashing vai de embate ao direito a transparência, essencial nas relações de consumo, inclusive positivado no Código de Defesa do Consumidor:

Art. $6^{\circ}$ São direitos básicos do consumidor:

(...)

III - a informação adequada e clara sobre os diferentes produtos e serviços, com especificação correta de quantidade, características, composição, qualidade e preço, bem como sobre os riscos que apresentem.

Quanto a essencialidade do princípio da transparência nas relações de consumo, Jorge Alberto Quadros de Carvalho Silva afirma que:

O princípio da transparência, essencialmente democrático que é, ao reconhecer que, em uma sociedade, o poder não é só exercido no plano da política, mas também da economia, surge no Código de Defesa do Consumidor, com o fim de regulamentar o poder econômico, exigindo-lhe visibilidade, ao atuar na esfera jurídica do consumidor (SILVA, 2003,p.56). 
Correlacionado ao princípio da transparência, há o princípio do Direito à informação, positivado no artigo 4 do Código de Defesa do Consumidor, sendo vedado, obviamente a informação falsa, como é o caso do greenwashin:

Art. $4^{\circ}$.A Política Nacional de Relações de Consumo tem por objetivo o atendimento das necessidades dos consumidores, o respeito a sua dignidade, saúde e segurança, a proteção de seus interesses econômicos, a melhoria da sua qualidade de vida, bem como a transparência e harmonia das relações de consumo, atendidos os seguintes princípios:

(...)

IV - educação e informação de fornecedores e consumidores, quanto aos seus direitos e deveres, com vistas à melhoria do mercado de consumo;

É nesse panorama, como meio de coibir a utilização do greenwashing, seja por uma afronta aos princípios elencados no Código de Defesa Consumidor, já por gerar danos ao movimento de defesa ambiental, que se defende pela aplicação da responsabilidade civil objetiva, sintetizada na possibilidade do causador do dano, mesmo que não tenha agido com culpa, se responsabilizar pela indenização em uma passível ação judicial, ante as consequências que perpassa um único indivíduo, posto o dano ser a uma coletividade.

\section{CONCLUSÃO}

O Direito ao Meio Ambiente salutar é identificado como um Direito Humano, na medida em que sua degradação acarreta em danos que ultrapassam as fronteiras nacionais, ademais, haja vista sua recepção no ordenamento pátrio brasileiro, tal direito ganha o status de fundamental.

Concomitantemente, na busca da preservação ambiental, cresce a concepção da responsabilidade ambiental pelo setor empresarial, cujo objetivo encontra-se na adoção de políticas capazes de minorar os danos ambientais.

Logo, a busca de um desenvolvimento sustentável, o qual acarrete menos danos e uma maior qualidade de vida a todos, deve ser objetivo não apenas do Estado, ou do cidadão, mas também das empresas, ou seja, é imprescindível a conscientização de todos os agentes e instituições sociais em prol de um bem comum, um meio ambiente ecologicamente equilibrado. 
Com o decorrer do tempo, as organizações perceberam que a política de preservação ambiental agrega valor ao produto, de modo que em virtude disto deu-se início a prática

Desta forma, conclui-se que um dos meios para coibir a prática do greenwashing está exatamente da possibilidade de aplicação da responsabilidade objetiva quando verificado a existência de uma propaganda enganosa.

\section{REFERÊNCIAS}

ASSOCIAÇÃO BRASILEIRA DE NORMAS TÉCNICAS. Os 7 Pecados da Rotulagem Ambiental. Disponível em:

https://www.abntonline.com.br/sustentabilidade/Rotulo/7pecados. Acesso em: 03 abr. 2019.

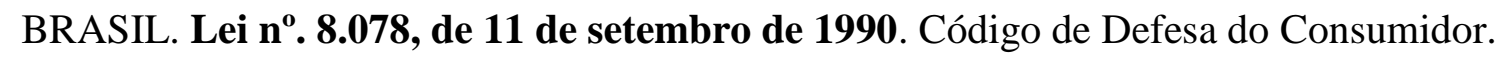
Dispõe sobre a proteção do consumidor e dá outras providências. Disponível em: http://www.planalto.gov.br/ccivil_03/Leis/L8078.htm

BOBBIO, Norberto. A Era dos Direitos. Tradução: Carlos Nelson Coutinho. 14 tir. Rio de Janeiro: Campus, 1992.

CAFÉ, Valéria. Durável desejável: como transformar o marketing na era da sustentabilidade. Revista da ESPM. Volume 17. Ano 16. Edição n. 1. Jan/Fev, 2010.

CHURCHIL Jr., Gilbert A.; PETER, J. Paul. Marketing: criando valor para o cliente. São Paulo: Saraiva, 2000.

CONAR. Boletim do Conar: ética na prática. Conselho Nacional de Autorregulamentação Publicitária. N. 203. Abr. 2014.

Conselho Nacional de Autorregulamentação Publicitária. Código Brasileiro de Autorregulamentação Publicitária. 2011.

Conselho Nacional de Autorregulamentação Publicitária. Representação nº 077/13, em recurso ordinário. Representado: Bombril. Relatores: Conselheiros César Augusto Massaioli e Letícia Lindenberg. Julgamento: mar. 2014.

CRUZ, Paulo Márcio; BODNAR, Zenildo. Cosmopolitismo e Governança transnacional Ambiental: uma Agenda para o Desenvolvimento Sustentável. In: Revista Direitos Humanos e Democracia. Editora. Unijuí. ano 4. n. 7. jan./jun. 2016. ISSN 2317-5389. Programa de Pós-Graduação Stricto Sensu em Direito da Unijuí. Disponível em:< https://www.revistas.unijui.edu.br/index.php/direitoshumanosedemocracia>. 
FOLADORI, Guilherme. Limites do desenvolvimento sustentável. Tradução de Marise Manoel. Campinas: Editora da Unicamp, 2001.

FRÓES, César; NETO, Francisco Paulo de Melo. Responsabilidade Social \& Cidadania Empresarial: a administração do terceiro setor. Rio de Janeiro: Qualitymark, 2002.

LAVORATO, Marilena Lino. Sustentabilidade, o princípio da lógica e coerência. Revista da ESPM. Volume 17. Ano 16. Edição n. 1. Jan/Fev, 2010.

LEITE. José Rubens Morato. “Sociedade de Risco e Estado". In: CANOTILHO, José Joaquim Gomes. LEITE, José Rubens Morato. Direito Constitucional Ambiental Brasileiro. São Paulo: Saraiva, 2007

LEWIS, Barbara R; LITTLER, Dale. (Org.) Dicionário Enciclopédico de Marketing. São Paulo: Atlas, 2001

KOTLER, Philip. Administração de marketing: a edição do novo milênio. São Paulo, Prentice Hall, 2000.

KOTLER, Philip; ARMSTRONG, Gary. Princípios de marketing. Rio de Janeiro: Prentice Hall, 1993.

KOTLER, Philip; ROBERTO, Eduardo L. Marketing social: estratégias para alterar o comportamento público. Rio de Janeiro: Campus, 1992.

MAKOWER, Joel. A economia verde. tradução Célio Knipel Moreira; revisão técnica Leonardo Abramowicz. São Paulo: Editora Gente, 2009.

MELO NETO, Francisco Paulo de, FROES, César. Responsabilidade social e cidadania: a administração do $3^{\circ}$ setor. Rio de Janeiro: Editora Qualitymark, 1999.

OTTMAN, Jacquelyn A. Marketing verde- Desafios e oportunidades para a nova era do marketing. São Paulo: Makron Books, 1994.

PAGOTTO, Érico Luciano. Greenwashing: os conflitos éticos da propaganda ambiental. 2013. 163 fls. Dissertação. Programa de Pós Graduação em Mudanças Sociais e Participação Política da EACH/USP. Universidade de São Paulo. São Paulo.

POLONSKY, Michael J. An Introducion to Green Merketing. Electronic Green Journal, 1994.

PRINGLE, Hamish; THOMPSON, Marjorie. Marketing social - marketing para causas sociais e a construção das marcas. 1. Ed. São Paulo: Majron Books, 2000.

SANTOS, Carlos Alberto Frantz dos; SILVA, Tânia Nunes da. Descompasso entre a consciência ambiental e a atitude ato de descartar o lixo eletrônico: A perspectiva do usuário residencial de uma empresa coletora. ENANPAD. Rio de Janeiro, 2011. 
SILVA, Jorge Alberto Quadros de carvalho. Responsabilidade objetiva: o Código Civil de 2002 e o Código de Defesa do Consumidor. Revista do Consumidor, São Paulo: RT, ano 14, n. 53, jan./mar., 2005 